OPEN ACCESS

Edited by:

Baokai Cui,

Beijing Forestry University, China

Reviewed by:

Olivier Raspé,

Botanic Garden Meise, Belgium

Damjan Franjevic,

University of Zagreb, Croatia

*Correspondence:

Andrew L. Loyd

aloyd@bartlett.com

Specialty section:

This article was submitted to

Fungi and Their Interactions,

a section of the journal

Frontiers in Microbiology

Received: 20 April 2018 Accepted: 22 June 2018

Published: 16 July 2018

Citation:

Loyd AL, Richter BS, Jusino MA,

Truong C, Smith ME, Blanchette RA

and Smith JA (2018) Identifying

the "Mushroom of Immortality": Assessing the Ganoderma Species

Composition in Commercial Reishi

Products. Front. Microbiol. 9:1557.

doi: 10.3389/fmicb.2018.01557

\section{Identifying the "Mushroom of Immortality": Assessing the Ganoderma Species Composition in Commercial Reishi Products}

\author{
Andrew L. Loyd ${ }^{1 *}$, Brantlee S. Richter ${ }^{2}$, Michelle A. Jusino², Camille Truong ${ }^{2,3}$, \\ Matthew E. Smith ${ }^{2}$, Robert A. Blanchette ${ }^{4}$ and Jason A. Smith ${ }^{1}$
}

${ }^{1}$ School of Forest Resources and Conservation, University of Florida, Gainesville, FL, United States, ${ }^{2}$ Department of Plant Pathology, University of Florida, Gainesville, FL, United States, ${ }^{3}$ Instituto de Biología, Universidad Nacional Autónoma de México (UNAM), Mexico City, Mexico, ${ }^{4}$ Department of Plant Pathology, University of Minnesota, St. Paul, MN, United States

Species of Ganoderma, commonly called reishi (in Japan) or lingzhi (in China), have been used in traditional medicine for thousands of years, and their use has gained interest from pharmaceutical industries in recent years. Globally, the taxonomy of Ganoderma species is chaotic, and the taxon name Ganoderma lucidum has been used for most laccate (shiny) Ganoderma species. However, it is now known that G. lucidum sensu stricto has a limited native distribution in Europe and some parts of China. It is likely that differences in the quality and quantity of medicinally relevant chemicals occur among Ganoderma species. To determine what species are being sold in commercially available products, twenty manufactured products (e.g., pills, tablets, teas, etc.) and seventeen grow your own (GYO) kits labeled as containing G. lucidum were analyzed. DNA was extracted, and the internal transcribed spacer (ITS) region and translation elongation factor 1 -alpha (tef1 $\alpha$ ) were sequenced with specific fungal primers. The majority (93\%) of the manufactured reishi products and almost half of the GYO kits were identified as Ganoderma lingzhi. G. lingzhi is native to Asia and is the most widely cultivated and studied taxon for medicinal use. Illumina MiSeq sequencing of the ITS1 region was performed to determine if multiple Ganoderma species were present. None of the manufactured products tested contained G. lucidum sensu stricto, and it was detected in only one GYO kit. G. lingzhi was detected in most products, but other Ganoderma species were also present, including G. applanatum, G. australe, G. gibbosum, G. sessile, and $G$. sinense. Our results indicate that the content of these products vary and that better labeling is needed to inform consumers before these products are ingested or marketed as medicine. Of the 17 GYO kits tested, 11 kits contained Ganoderma taxa that are not native to the United States. If fruiting bodies of exotic Ganoderma taxa are cultivated, these GYO kits will likely end up in the environment. The effects of these exotic species to natural ecosystems needs investigation.

\footnotetext{
Keywords: reishi, lingzhi, Ganoderma lucidum, dietary supplements, Polyporales
} 


\section{INTRODUCTION}

Ganoderma is a large and diverse, globally distributed genus of wood decay fungi that includes species that cause white rot on a variety of tree species. In addition, practitioners of Eastern traditional medicine have prescribed the use of laccate (shiny) Ganoderma species, commonly referred to as "reishi" or "lingzhi," as a preventative anti-inflammatory treatment or to enhance immunity (Wang et al., 2012; Hennicke et al., 2016). In Asian countries, reishi (this term will be used in this paper to refer to both reishi and lingzhi) products have been used for over 2000 years, and Ganoderma has been revered as "the mushroom of immortality" (Stamets, 2000). Reishi is a focal point in ancient Chinese and Japanese artwork and has been associated with royalty, wisdom, sexual prowess, and eternal life (Stamets, 2000). According to Chinese and American pharmacopeias, reishi is considered as an elixir for a wide variety of ailments (Sanodiya et al., 2009).

References to reishi as a superior herb that enhances human health can be found as early as 100 B.C. (Cao et al., 2012). Currently, members of the G. lucidum species complex continue to be prescribed in traditional medicine, for which fruiting bodies are typically grown, ground, and made into pills, tinctures, or teas (Stamets, 2000). In the American Herbal Pharmacopeia, G. lucidum sensu lato is mostly recommended for immune enhancing effects (Upton and Petrone, 2000; Jin et al., 2012). In addition, Eastern traditional medicine is becoming popular worldwide, and the reishi industry is quite profitable, with a world trade value of greater than $\$ 2.16$ billion (Lai et al., 2004; Cao et al., 2012). The dietary supplement industry, which consists of vitamins, minerals, botanicals, etc., is a growing market with global sales at $\$ 109$ billion, with an expectation of nearly doubling the sales by 2020 (Binns et al., 2017). Based on these figures, the reishi industry accounts for approximately $2 \%$ of the worldwide dietary supplement sales.

Recent research has reported that G. lucidum sensu lato contains approximately 400 bioactive compounds that are mostly polysaccharides and triterpenes (Sanodiya et al., 2009; Basnet et al., 2017). These compounds have anti-inflammatory, radical oxygen scavenging, anti-tumor, immune-enhancing, and antimicrobial activities (Paterson, 2006; Boh et al., 2007; Sanodiya et al., 2009; Jin et al., 2012). G. lucidum sensu lato produces the antifungal protein ganodermin, which has inhibitory effects against common fungi such as Botrytis cinerea and Fusarium oxysporum (Wang and Ng, 2006), and also produces other chemicals with antibacterial effects (Isaka et al., 2015; Basnet et al., 2017). Antiviral properties of triterpenes produced by another laccate species, Ganoderma pfeifferi, were shown to be active against influenza virus A (Mothana et al., 2003). Finally, nematacidal properties were observed when Ganoderma extracts were applied to Heterodera glycines (Zhao et al., 2009). In addition to these inhibitory effects against other microbes, reishi is mostly recommended for enhancing immunity (Upton and Petrone, 2000; Jin et al., 2012), with preventative qualities such as anti-inflammatory, anti-allergenic, radical oxygen scavenging, as well as inhibitory effects of tumor growths (Lin et al., 1991; Paterson, 2006; Powell, 2006; Boh et al., 2007;
Joseph et al., 2009; Sanodiya et al., 2009; Jin et al., 2012). The chemical and biological properties of many fungi have sparked the interest of pharmaceutical researchers who are investigating secondary metabolites produced by fungi that may lead to the biomanufacturing of new drug formulations (Zhong and Xiao, 2009).

The taxonomy of the laccate Ganoderma species is quite convoluted, and the taxonomy and phylogenetic relationships among taxa are still being actively investigated (Moncalvo et al., 1995a; Hong and Jung, 2004; Cao et al., 2012; Wang et al., 2012; Zhou et al., 2015). For the past century, many studies of Ganoderma have used the name G. lucidum for any laccate Ganoderma species growing on hardwood trees (Pirone, 1957; Gilbertson and Ryvarden, 1986; Sinclair and Lyon, 2005; Zhou et al., 2015). Similarly, commercially available grow your own (GYO) reishi kits and vitamin supplements produced and marketed as traditional medicine are sold broadly as G. lucidum. Molecular studies have established that G. lucidum sensu stricto (Curtis) Karst has a native geographic distribution in Europe and some parts of China, while Ganoderma lingzhi Sheng H. Wu, Y. Cao, and Y.C. Dai is native from East Asia (Cao et al., 2012). Furthermore, as of this writing, G. lucidum sensu lato has been divided in to numerous distinct species (Welti and Courtecuisse, 2010; Cao et al., 2012; Wang et al., 2012; Zhou et al., 2015; Dai et al., 2017). The medicinal species most widely used is G. lingzhi, which has different morphological and genetic characteristics than G. lucidum.

Chemical constituents of mushrooms are generally expected to differ among species within a genus. For example, Kalogeropoulos et al. (2013) found significant differences among three species of Lactarius in production of sterols, phenolic acids, hydroxycinnamic acids, phenols, flavonoids, Stilbenes, and terpenic acids. In medicinal fungi, such as Fomes fomentarius, Fomitopsis pinicola, and Piptoporus betulina, individual isolates growing across different environments have also been shown to vary in the pharmacological constituents produced in fruiting bodies (Dresch et al., 2015). The chemical profiles of G. lucidum sensu stricto, a European species, and G. lingzhi, an Asian species, differ significantly in the amount of triterpenic acid produced in the basidiomata (Hennicke et al., 2016). Although a thorough analysis of chemical compositions has not yet been performed, it is probable that triterpenes and other bioactive chemical compositions vary across different phylogenetically supported Ganoderma taxa formerly included under the name G. lucidum (Hennicke et al., 2016).

In the United States, the Food and Drug Administration (FDA) does not regulate the marketing of fungal medicinal products. As with other herbal supplements, the lack of regulation can create a "buyer beware" market, because the integrity of the product lies with the manufacturer (Paterson, 2006; Raja et al., 2017). With the current rapidly changing understanding of Ganoderma characteristics among species, even well-intentioned manufacturers may have difficulty ensuring that their product contains the labeled species. Several Chinese species once called G. lucidum are now considered to belong to other species, including Ganoderma flexipes, G. lingzhi, Ganoderma multipileum, Ganoderma sichuanense, G. sinense, 
and Ganoderma tropicum (Wang et al., 2009, 2012; Cao et al., 2012; Hennicke et al., 2016; Raja et al., 2017). Surveys of consumer-relevant mushroom supplements have shed some light on the taxonomic identification of reishi; in a survey of multiple fungal supplement products, none of the six reishi products successfully tested with DNA barcoding methods contained G. lucidum, despite being labeled as "G. lucidum" (Raja et al., 2017). Furthermore, a study of chemical profiles identified by chromatography found that approximately $75 \%$ of reishi products sold in the United States are not consistent with the chemical profiles of G. lucidum sensu stricto (Wu et al., 2017). The goal of this research project was to survey what Ganoderma species were present in GYO kits and manufactured reishi products sold as dietary supplements, using traditional and next-generation DNA-based molecular techniques.

\section{MATERIALS AND METHODS}

\section{Sample Collection}

Seventeen GYO kits that were marketed for medicinal use were purchased from mushroom cultivation companies in the United States. These kits were sold as colonized wooden dowels $(n=8)$, sawdust inoculum $(n=7)$, or mycelial suspensions in syringes $(n=2)$. All of the kits were labeled as containing G. lucidum, except one that was labeled as containing Ganoderma curtisii. However, one GYO kit was labeled with G. lucidum sensu lato, acknowledging the ambiguity of this species. Furthermore, two manufactured reishi products were labeled as containing a combination of fungal species: (1) G. lucidum and Lentinula edodes, or shiitake (product AL-R4) and (2) Ganoderma tsugai (presumably the improper spelling of G. tsuage), G. lucidum, and G. applanatum (product AL-R11). In addition, twenty commercially available, manufactured reishi products were purchased based on the following criteria: (i) readily available for purchase online, (ii) labeled as including G. lucidum, and (iii) marketed with medicinal benefits. Manufactured reishi products were sold as capsules $(n=13)$, powders $(n=3)$, tablets $(n=1)$, coffee $(n=1)$ or tea $(n=1)$. With the exception of two products labeled as G. lucidum sensu lato, acknowledging the ambiguity of the species G. lucidum, all products were labeled as "G. lucidum" with health-promoting marketing statements such as "supports longevity," "supports immune system," "detoxifier," and "botanical immune support." In addition, all manufactured products contained the following label: "These statements have not been evaluated by the Food and Drug Administration. This product is not intended to diagnose, treat, cure or prevent any diseases."

Culturing and vouchering GYO reishi kits-Isolations from each GYO kit were made by excising small pieces $\left(<1 \mathrm{~mm}^{3}\right)$ of spawn inoculum with a sterile scalpel and placing them onto 2\% malt extract agar (MEA) (Difco Laboratories, Franklin Lakes, NJ, United States) prepared according to the manufacturer's instructions with the addition of streptomycin (100 mg/l), 95\% benomyl (4 mg/l), and $85 \%$ lactic acid $(2 \mathrm{ml} / \mathrm{l})$, which help to limit bacterial and the growth of fungi in the Ascomycota. Cultures were maintained on MEA slants as working stocks, and colonized agar disks were submerged in sterile water for long term storage (Marx and Daniel, 1976). Culture collections (ALM1-ALM17) were archived in the Center for Forest Mycology Research (CFMR) Culture Collection and Herbarium, USDA Forest Service, maintained by the Northern Research Station and housed in the Forest Products Laboratory, USDA-Forest Service in Madison, Wisconsin.

\section{Microscopic Analysis}

The mycelium from the GYO kits was visualized in $5 \% \mathrm{KOH}$ on glass slides using a Nikon Eclipse 55i light microscope (Melville, NY) to determine the presence/absence of chlamydospores, which are diagnostic features for some of the laccate Ganoderma species (Nobles, 1965; Hong and Jung, 2004). Two slide mounts were made for each GYO kit by taking mycelium from the center of the colony of a mature (eight-day-old) culture grown on MEA. These slides were visualized at $40 \times$ magnification, and scanned for the presence/absence of chlamydospores. Similarly, reishi supplement products were visualized on slide mounts with $5 \%$ $\mathrm{KOH}$ to look for any distinguishing microscopic features. Two slide mounts were made for each manufactured reishi products by crushing products (if necessary) and placing a small amount $(<1 \mathrm{mg})$ of powder in a drop of $\mathrm{KOH}$. Samples were then visualized at $40 \times$ by scanning each slide and thoroughly noting any features such as basidiospores, generative hyphae, skeletal hyphae, and chlamydospores. These features were used to deduce whether the products were made with immature basidiomata, mature basidiomata, vegetative cultures, or basidiospores.

\section{DNA Extraction, PCR, and Sanger Sequencing}

DNA was extracted from each reishi supplement product and mycelium from GYO kit spawn with the Qiagen DNeasy Plant Mini Kit (Qiagen, Hilden, Germany) according to the manufacturer's instructions. The internal transcribed spacer (ITS) region of the ribosomal DNA (rDNA) was amplified by PCR with primers ITS1F (5' CTT GGTCATTTAGAGGAAGTAA) and ITS4b (5' CAGGAGA CTTGTACACGGTCCAG) (White et al., 1990; Gardes and Bruns, 1993) to identify Ganoderma species present in the sample. ITS is the universal fungal barcode for fungi that is commonly used for species delimitation (Schoch et al., 2012). In addition, the translation elongation factor 1-alpha (tefl $\alpha)$ was sequenced for all of the GYO kits using primers EF-Gano23F (5' GGTGTCAGGCAGCTCATYGT) and EF-Gano887R (5' CGAACTTGCARGCGATGTG), which were developed specifically for amplification of laccate Ganoderma species. For each PCR reaction, the following reagents were used: $12.5 \mu \mathrm{l}$ of Immomix Red Master Mix (Bioline, London, United Kingdom), $8.5 \mu \mathrm{l}$ of PCR-grade $\mathrm{H}_{2} \mathrm{O}, 1 \mu \mathrm{l}$ BSA $(20 \mathrm{mg} / \mathrm{ml}$, Thermo Fisher Scientific, Waltham, MA, United States), $1 \mu$ l of each $10 \mathrm{mM}$ primer, and $1 \mathrm{ng} / \mu \mathrm{l}$ of DNA template. Reactions were performed on a MJ Mini thermocycler (Bio-Rad, Hercules, CA, United States) with the following thermocycler conditions: cycle of $95^{\circ} \mathrm{C}$ for $10 \mathrm{~min}$ and followed by $35^{\circ}$ cycles of $94^{\circ} \mathrm{C}$ for $30 \mathrm{~s}$, variable annealing temperatures of $55^{\circ} \mathrm{C}$ (ITS) or 
$62^{\circ} \mathrm{C}($ tef $1 \alpha)$ for $30 \mathrm{~s}$, and $72^{\circ} \mathrm{C}$ for $1 \mathrm{~min}$, followed by a final extension step of $72^{\circ} \mathrm{C}$ for $5 \mathrm{~min}$, and then $4^{\circ} \mathrm{C}$. PCR products were visually assessed on a $1 \%$ agarose gel that was stained with Gel Red (Biotium, Fremont, CA, United States) to confirm successful amplification. Amplicons were purified with ExoSAP-IT (Thermo Fisher Scientific, Waltham, MA, United States) according to the manufacturer's recommendations. Sanger sequencing was performed using the same primers through the Genewiz $^{1}$ sequencing lab. Forward and reverse sequences for each sample were aligned and visually edited using GENEIOUS 10 (Kearse et al., 2012). All Sanger sequences generated were deposited and accessioned in the GenBank sequence database (see below). ITS and tefl $\alpha$ sequences were queried against an in-house database of all known Ganoderma species (Zhou et al., 2015). Identifications were based on 99-100\% homology with reliable reference sequences.

\section{Illumina Meta-Barcoding Sequencing}

If multiple taxa were present in an individual sample, Sanger sequencing would either yield a clean DNA sequence only for the dominant taxon or would yield a mixed sequence that would not be readable due to multiple overlapping sequence peaks. Accordingly, we performed Illumina metabarcoding sequencing in addition to Sanger sequencing for all of the manufactured reishi products because these are the products that are most likely to contain multiple species based on the recommendation of Raja et al. (2017). DNA was extracted from the 20 manufactured reishi products as described previously, and all were subject to Illumina metabarcoding sequencing. Following extraction, DNA concentration was measured using a NanoDrop 2000 (Thermo Fisher Scientific, Waltham, MA, United States), and samples were equilibrated pre-PCR to $5 \mathrm{ng} / \mu \mathrm{l}$. For each PCR reaction, the following reagents were used: $12.5 \mu \mathrm{l}$ of Phusion High-Fidelity PCR Mix (New England Biolabs, Ipswich, MA, United States), $1.25 \mu \mathrm{l}$ of each forward and reverse $5 \mu \mathrm{M}$ primer, and 510 ng DNA. The ITS1 rDNA was amplified with fungal-specific primers ITS1f (Gardes and Bruns, 1993) and ITS2 (White et al., 1990) using eight i5 (forward) and three i7 (reverse) TruSeq barcoded adapters (Illumina, San Diego, CA, United States). PCR conditions were: denaturation at $94^{\circ} \mathrm{C}$ for $1 \mathrm{~min}$ followed by 30 cycles at $94^{\circ} \mathrm{C}$ for $30 \mathrm{~s}, 52^{\circ} \mathrm{C}$ for $30 \mathrm{~s}, 68^{\circ} \mathrm{C}$ for $30 \mathrm{~s}$ and final extension at $68^{\circ} \mathrm{C}$ for $7 \mathrm{~min}$, using 5-10 ng DNA. As a positive control, a six-species mock community was constructed using equimolar concentrations of DNA extracted from pure MEA cultures of GYO kits or wild collections. In addition, a negative PCR water control was used. Amplicons were verified on $1.5 \%$ agarose gels stained with SYBR Green (Invitrogen, Carlsbad, CA, United States) and normalized at equimolar concentration with the SequalPrep Normalization Plate Kit (Thermo Fisher Scientific, Waltham, MA, United States). If PCR bands were absent on the gel ( $n=5, \mathrm{AL}-\mathrm{R} 4, \mathrm{AL}-\mathrm{R} 9, \mathrm{AL}-\mathrm{R} 10, \mathrm{AL}-\mathrm{R} 12$, and AL-R19), samples were prepared as the other samples, except PCR products were not diluted. The library was purified with the Agencourt AMPure XP kit (Beckman Coulter, Brea, CA, United States) to remove primer dimers before sequencing with

${ }^{1}$ www.genewiz.com a MiSeq 300 bp paired-end protocol (Illumina, San Diego, CA, United States) at the Interdisciplinary Center for Biotechnology of University of Florida. Raw data are available at NCBI's SRA BioProject Accession SRP149732.

\section{Illumina Meta-Barcoding Analysis}

Illumina sequence data were processed using the AMPtk pipeline (version 1.1 .0$)^{2}$. Briefly, the overlapping $2 \times 300$ Illumina MiSeq reads were merged using USEARCH (version 9.2.64; Edgar and Flyvbjerg, 2015), all primers were removed from the merged reads. All reads that were less than 150 bp were removed. Reads that were less than 300 bp were padded with N's, and those that were more than $300 \mathrm{bp}$ were trimmed. This trimming/padding step improves clustering and other downstream steps (Palmer et al., 2018). Reads were then quality filtered with expected errors less than 1.0 (Edgar and Flyvbjerg, 2015), de-replicated, and clustered at $97 \%$ similarity, the broadly accepted cutoff to approximate species in fungi (Kõljalg et al., 2013), using UPARSE. All singleton OTUs were removed. The resulting OTU table was then filtered for index bleed at $0.5 \%$, following Palmer et al. (2018). Taxonomy was assigned using the hybrid taxonomy approach in AMPtk. In order to verify the identities of the resultant OTUs, 60 ITS sequences that included reliable reference sequences as well as those generated from Sanger and Illumina sequences (Table 1) were aligned using the MAFFT (Katoh et al., 2002) plugin in GENEIOUS 10. The alignment was visually edited to remove any ambiguities and minimize differences that could have resulted from sequencing error. Visually edited alignments of each locus were used for independent phylogenetic analyses using maximum likelihood implemented in RAxML (Stamatakis, 2014) and a Bayesian inference using MrBayes (Ronquist et al., 2012) plugins in Geneious 10. The RaxML analysis used a general time reversal (GTR) evolutionary model with rapid bootstrapping and 1000 bootstrap replications, and the Bayesian analysis used a GTR evolutionary model with a gamma rate variation using four gamma categories, for one million generations with 4 heated chains and a burn-in length of 100,000. These unrooted trees were produced to place ITS sequences and ITS1 OTUs generated from Sanger and Illumina sequencing into lineages identified based on reliable reference sequences (Figure 1). The alignments and trees have been deposited to Treebase under submission \#22867.

\section{RESULTS}

\section{Microscopic Analysis}

Of the GYO kits, $100 \%$ of the pure cultures had generative hyphae with clamp connections and were consistent with in vitro colony morphology of Ganoderma (Nobles, 1965; Adaskaveg and Gilbertson, 1989). Forty-one percent $(n=7)$ of the seventeen GYO kits constitutively produced smooth, intercalary to terminal, double-walled, hyaline, ovate to obpyriform chlamydospores that are consistent with species in the Ganoderma resinaceum clade (Hong and Jung, 2004).

\footnotetext{
${ }^{2}$ http://amptk.readthedocs.io
} 
TABLE 1 | Sample labels, species, locations, product types and ITS GenBank Accession numbers for commercial reishi products and reference sequences used in the phylogenetic analysis.

\begin{tabular}{|c|c|c|c|c|}
\hline Sample & Species $^{1}$ & GenBank ITS Accession ${ }^{2}$ & Specimen Type or Location ${ }^{3}$ & Authors ${ }^{4}$ \\
\hline AL-R6 & Ganoderma applanatum & MH160077 & Manufactured product & this study \\
\hline $\mathrm{BHI}-\mathrm{F} 418 \mathrm{a}$ & G. applanatum & MF161255.1 & MA, United States & Haelewaters et al., 2018 \\
\hline CFMR-DLL2011-056 & G. applanatum & KJ140577.1 & WI, United States & Brazee et al., 2014 \\
\hline OTU5 & G. applanatum & NA & Manufactured product & this study \\
\hline JM97/56 & Ganoderma australe (species complex) & AF255099.1 & NC, United States & Moncalvo and Buchanan, 2008 \\
\hline JM98/1 & G. australe (species complex) & AF255100.1 & NC, United States & Moncalvo and Buchanan, 2008 \\
\hline OTU292 & G. australe (species complex) & NA & Manufactured product & this study \\
\hline AL-M17 & Ganoderma curtisii & MH160072 & GYO Reishi Kit & this study \\
\hline AL-M8 & G. curtisii & MH160063 & GYO Reishi Kit & this study \\
\hline CBS100131 & G. curtisii & JQ781848 & NC, United States & Cao et al., 2012 \\
\hline CBS100132 & G. curtisii & JQ781849 & NC, United States & Cao et al., 2012 \\
\hline OTU31 & Ganoderma gibbosum & NA & Manufactured product & this study \\
\hline SPC10 & G. gibbosum & KU569554.1 & Brazil & Bolanos et al., 2016 \\
\hline UB1 & G. gibbosum & KU569556.1 & Brazil & Bolanos et al., 2016 \\
\hline AL-M10 & Ganoderma lingzhi & MH160065 & GYO Reishi Kit & this study \\
\hline AL-M11 & G. lingzhi & MH160066 & GYO Reishi Kit & this study \\
\hline AL-M12 & G. lingzhi & $\mathrm{MH} 160067$ & GYO Reishi Kit & this study \\
\hline AL-M15 & G. lingzhi & $\mathrm{MH} 160070$ & GYO Reishi Kit & this study \\
\hline AL-M3 & G. lingzhi & MH160058 & GYO Reishi Kit & this study \\
\hline AL-M6 & G. lingzhi & $\mathrm{MH} 160061$ & GYO Reishi Kit & this study \\
\hline AL-M9 & G. lingzhi & MH160064 & GYO Reishi Kit & this study \\
\hline AL-R1 & G. lingzhi & MH160073 & Manufactured product & this study \\
\hline AL-R10 & G. lingzhi & MH160081 & Manufactured product & this study \\
\hline AL-R13 & G. lingzhi & MH160082 & Manufactured product & this study \\
\hline AL-R14 & G. lingzhi & $\mathrm{MH} 160083$ & Manufactured product & this study \\
\hline AL-R15 & G. lingzhi & MH160084 & Manufactured product & this study \\
\hline AL-R17 & G. lingzhi & MH160085 & Manufactured product & this study \\
\hline AL-R19 & G. lingzhi & MH160086 & Manufactured product & this study \\
\hline AL-R2 & G. lingzhi & $\mathrm{MH} 160074$ & Manufactured product & this study \\
\hline AL-R3 & G. lingzhi & $\mathrm{MH} 160075$ & Manufactured product & this study \\
\hline AL-R5 & G. lingzhi & MH160076 & Manufactured product & this study \\
\hline AL-R7 & G. lingzhi & MH160078 & Manufactured product & this study \\
\hline AL-R8 & G. lingzhi & MH160079 & Manufactured product & this study \\
\hline AL-R9 & G. lingzhi & MH160080 & Manufactured product & this study \\
\hline Cui9166 & G. lingzhi & KJ143907 & China & Zhou et al., 2015 \\
\hline Dai12479 & G. lingzhi & JQ781864 & China & Cao et al., 2012 \\
\hline OTU1 & G. lingzhi & NA & Manufactured product & this study \\
\hline AL-M16 & Ganoderma lucidum & MH160071 & GYO Reishi Kit & this study \\
\hline MT26/10 & G. lucidum & KJ143912 & Czech Republic & Zhou et al., 2015 \\
\hline Rivoire4195 & G. Iucidum & KJ143909 & France & Zhou et al., 2015 \\
\hline CBS194.76 & Ganoderma resinaceum & KJ143916 & Netherlands & Zhou et al., 2015 \\
\hline Rivoire4150 & G. resinaceum & KJ143915 & France & Zhou et al., 2015 \\
\hline AL-M13 & G. resinaceum s.l. & $\mathrm{MH} 160068$ & GYO Reishi Kit & this study \\
\hline AL-M14 & G. resinaceum s.l. & MH160069 & GYO Reishi Kit & this study \\
\hline AL-M7 & G. resinaceum s.l. & MH160062 & GYO Reishi Kit & this study \\
\hline OTU4 & G. resinaceum s.l. & NA & Manufactured product & this study \\
\hline AL-M1 & Ganoderma sessile & MH160056 & GYO Reishi Kit & this study \\
\hline AL-M2 & G. sessile & MH160057 & GYO Reishi Kit & this study \\
\hline AL-M4 & G. sessile & MH160059 & GYO Reishi Kit & this study \\
\hline AL-M5 & G. sessile & MH160060 & GYO Reishi Kit & this study \\
\hline JV1209/27 & G. sessile & KF605630 & AZ, United States & Zhou et al., 2015 \\
\hline NY00985711 & G. sessile & KJ143918 & NY, United States & Zhou et al., 2015 \\
\hline
\end{tabular}


TABLE 1 | Continued

\begin{tabular}{|c|c|c|c|c|}
\hline Sample & Species $^{1}$ & GenBank ITS Accession² & Specimen Type or Location ${ }^{3}$ & Authors $^{4}$ \\
\hline OTU6 & G. sessile & NA & Manufactured product & this study \\
\hline OTU164 & Ganoderma sinense & NA & Manufactured product & this study \\
\hline Wei5327 & G. sinense & KF494998.1 & China & Zhao and Cui, 2013 \\
\hline LIPSW-Mart08-45 & Ganoderma tuberculosum & KF963258.1 & French West Indies & Lesage-Meesen et al., 2014 \\
\hline OTU15 & G. tuberculosum & NA & Manufactured product & this study \\
\hline PLM684 & G. tuberculosum & MG654369 & FL, United States & Loyd, 2018 \\
\hline Cui7691 & Ganoderma weberianum & JQ781878 & China & Cao et al., 2012 \\
\hline HMAS42798 & Ganoderma weberianum & JQ781877 & China & Cao et al., 2012 \\
\hline
\end{tabular}

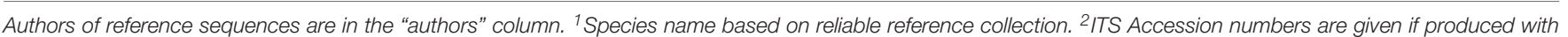

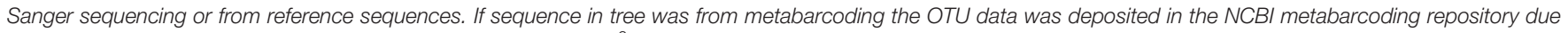

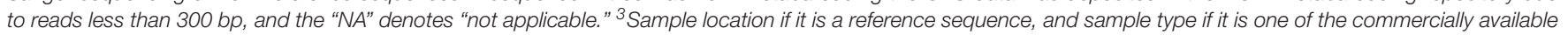
reishi products. ${ }^{4}$ Authors of the sequence from GenBank, unless published. If published, then the publication first author and year is cited.

No other diagnostic structures were observed in the vegetative mycelium of the other GYO kit products. Thirty-five percent $(n=7)$ of the manufactured reishi products were putatively made with mature fruiting bodies, based on the identification of generative and skeletal hyphae and basidiospores. Twenty-five percent $(n=5)$ were putatively made with immature fruiting bodies (generative and skeletal hyphae, no basidiospores), twenty percent $(n=4)$ were putatively made with cultures (generative hyphae only), and ten percent $(n=2)$ were putatively made with only basidiospores. Five percent ( $n=1$, AL-R15-coffee) of the manufactured products had no definitive Ganoderma tissues based on our slide mounts (Table 2).

\section{Identification Based on Sanger Sequencing}

ITS sequences were successfully amplified for $100 \%(n=17)$ of the GYO kit samples and $70 \%(n=14$ of 20$)$ of the manufactured reishi products. Sequences of tef $1 \alpha$ were successfully generated for $100 \%(n=17)$ of the GYO kit samples and amplification of the manufactured reishi products was not attempted. The 31 ITS sequences (MH160056-MH160086) and 17 tef1 $\alpha$ sequences (MH168053-MH168069) were deposited in Genbank. Of the GYO kits, two products were correctly labeled as G. curtisii (ALM17) and G. lucidum (AL-M16). The other 15 GYO kits were mislabeled as G. lucidum, and were actually identified as G. lingzhi $(n=7)$, G. sessile $(n=4), G$. resinaceum sensu lato $(n=3)$, or G. curtisii $(n=1)$. All of the manufactured reishi products for which we generated sequences were mislabeled as G. lucidum, and subsequently identified with Sanger sequencing as G. lingzhi, except one sample (AL-R6) that was identified as G. applanatum. These results are presented in Table 1.

\section{Identification Based on Illumina Meta-Barcoding}

Amplification and sequencing of the genomic library was successful for 19 of the 20 manufactured reishi products tested (AL-R12 failed). All successfully sequenced manufactured reishi products $(n=19)$ contained at least one Ganoderma species (Table 3). However, G. lucidum sensu stricto was not detected in any of the products. Three products each contained only a single Ganoderma species detected by Illumina meta-barcoding: G. applanatum in AL-R6 and G. lingzhi in AL-R7 and AL-R14 (Figure 2). We also detected multiple Ganoderma species in 16 of the 19 manufactured products. Because of PCR biases linked to next-generation sequencing methods, the quantification of species abundance in a community based on the abundance of sequences in a sample is not generally considered reliable (Palmer et al., 2018). However, we were able to detect the six species of our mock community in our positive control with relatively little bias (read numbers range from 6,015 to 51,020). In addition, our negative control yielded only one OTU that was not present in any of our samples, nor was a band observed of the PCR product with gel electrophoresis as described previously. We therefore used the relative abundance of sequences to quantify the presence of Ganoderma spp. in each sample (Table 2). The majority of products $(74 \%, n=14)$ contained a high abundance of $G$. lingzhi sequences, with only negligible numbers of sequences $(<5 \%$ of the reads) from other species of Ganoderma or other relevant taxa. Five out of the 19 successfully sequenced products had $>5 \%$ sequence abundance from other Ganoderma or relevant fungal species other than G. lingzhi (Figure 2).

The maximum likelihood and Bayesian phylogenies constructed with sequences from Sanger and Illumina sequencing gave identical results, so only the unrooted RAxML phylogeny is presented (Figure 1). The ITS sequences generated in this study clustered with significant statistical support with the reference sequences.

\section{DISCUSSION}

The results of this study highlight the taxonomic problems surrounding the medicinal marketing of the laccate Ganoderma species that are used for cultivation spawn and/or sold as manufactured products (i.e., dietary supplements). The majority of the GYO kits and manufactured reishi products indicated that they were made with "Ganoderma lucidum." However, no manufactured reishi products and only one GYO kit (AL-M16) actually contained G. lucidum sensu stricto. The incorrect identification of Ganoderma species in these products is presumed to be non-intentional and likely due to the complicated 


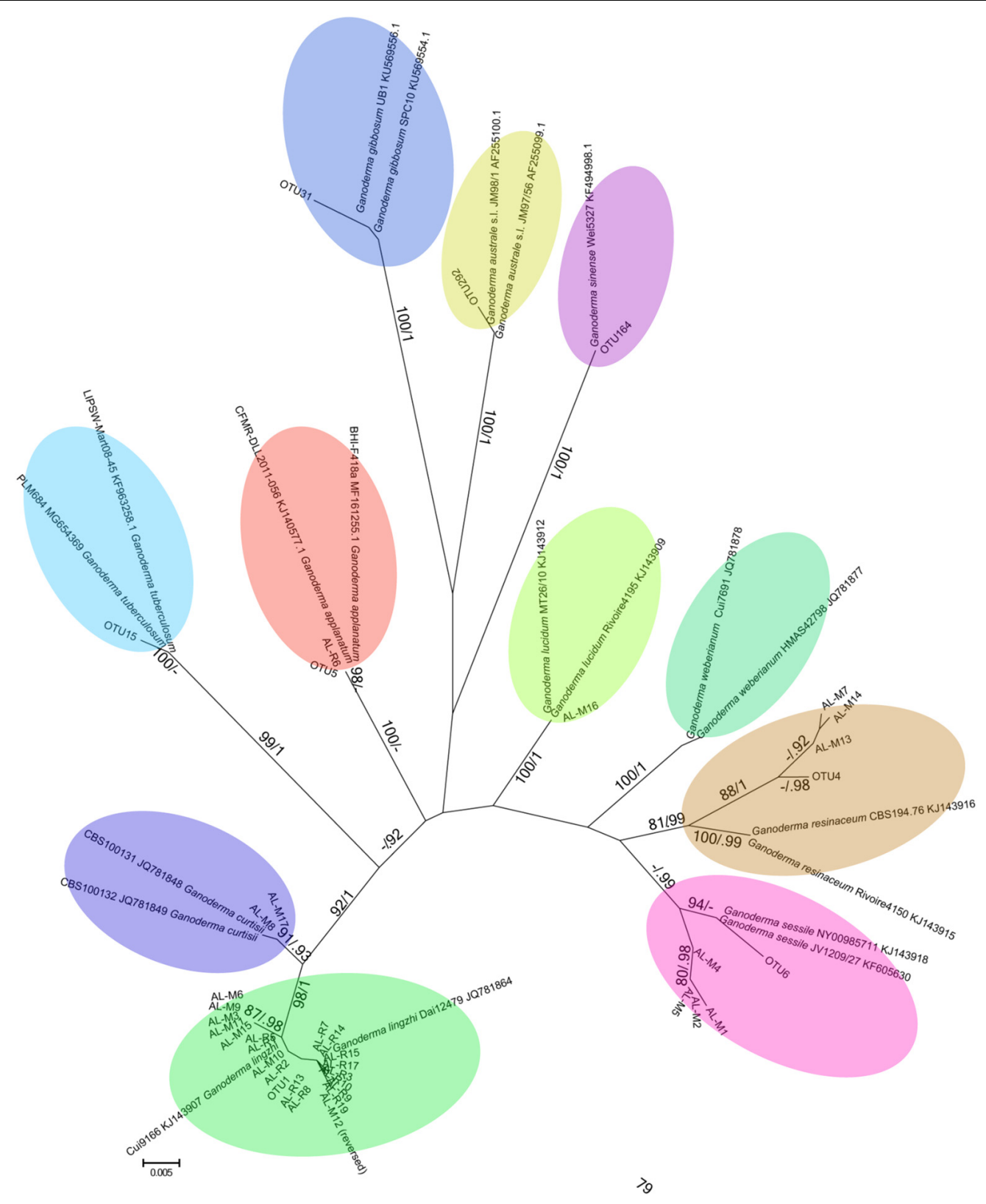

FIGURE 1 | Unrooted maximum likelihood phylogenetic tree reconstructed using ITS sequences generated in this molecular survey together with reliable reference sequences for identification at the species level. Bootstrap values are indicated on branches, followed by the posterior probability of the Bayesian phylogeny that had identical topology. Reference sequences are annotated with species names and GenBank Accession numbers. Clusters of sequences shaded were found in this study, and sequence branches with the same color are the same species. Reference sequences for $G$. weberianum were included to show the relationship to the G. resinaceum sensu lato species identifications. Sequences generated with Sanger sequencing are labeled as AL-M\# (GYO reishi kits) and AL-R\# (manufactured products), and sequences generated with Illumina MiSeq are labeled as OTU\# (manufactured products).

taxonomic problems within the laccate Ganoderma as well as the nomenclatural changes that have occurred in recent years (Cao et al., 2012; Wang et al., 2012; Zhou et al., 2015; Hennicke et al., 2016; Dai et al., 2017). In North America and around the world, many laccate Ganoderma species have been overlooked or treated as synonyms of G. lucidum for the past century. For example, the genome of G. lucidum that was sequenced as the model medicinal mushroom by Chen et al. (2012), is actually G. lingzhi based on the $r p b 1$ and $r p b 2$ DNA regions. Previous phylogenetic studies hypothesized that Ganoderma species have a vicariant pattern of evolution, wherein subclades typically contains sister taxa in North America and in Asia-Europe (e.g., G. curtisii and G. lingzhi) or geographically separated regions within North America (e.g., Ganoderma tsugae and Ganoderma oregonense) (Gilbertson and Ryvarden, 1986; Cao et al., 2012; Zhou et al., 2015; Hennicke et al., 2016). Based on these phylogenetic 
TABLE 2 | Summary of the Sanger sequencing results comparing the product (GYO reishi kits and manufactured reishi products) taxonomy labels to the DNA-based barcode identification.

\begin{tabular}{|c|c|c|c|c|}
\hline Sample \# $\#^{1}$ & Product $^{2}$ & Product Label $^{3}$ & Taxon Identified ${ }^{4}$ & GB ITS/tef1 $\alpha$ Accession \\
\hline $\mathrm{AL}-\mathrm{M} 1_{\mathrm{sd}}$ & GYO reishi kit & G. Iucidum & G. sessile ${ }_{c h}$ & MH160056/MH168053 \\
\hline $\mathrm{AL}-\mathrm{M} 2_{\mathrm{cd}}$ & GYO reishi kit & G. lucidum & G. sessile $\mathrm{ch}$ & MH160057/MH168054 \\
\hline $\mathrm{AL}-\mathrm{M3}_{\mathrm{sy}}$ & GYO reishi kit & G. lucidum & G. lingzhi & MH160058/MH168055 \\
\hline $\mathrm{AL}-\mathrm{M} 4_{\mathrm{cd}}$ & GYO reishi kit & G. lucidum & G. sessile ${ }_{\mathrm{ch}}$ & MH160059/MH168056 \\
\hline $\mathrm{AL}-\mathrm{M} 5_{\mathrm{Cd}}$ & GYO reishi kit & G. lucidum & G. sessile $\mathrm{ch}$ & MH160060/MH168057 \\
\hline$A L-M 6_{s d}$ & GYO reishi kit & G. lucidum & G. lingzhi & MH160061/MH168058 \\
\hline $\mathrm{AL}-\mathrm{M} 7_{\mathrm{Cd}}$ & GYO reishi kit & G. lucidum s.I. & G. resinaceum s.l.ch & MH160062/MH168059 \\
\hline $\mathrm{AL}-\mathrm{M} 8_{\mathrm{Cd}}$ & GYO reishi kit & G. lucidum & G. curtisii & MH160063/MH168060 \\
\hline$A L-M 9_{s d}$ & GYO reishi kit & G. lucidum & G. lingzhi & MH160064/MH168061 \\
\hline$A L-M 10_{s d}$ & GYO reishi kit & G. lucidum & G. lingzhi & MH160065/MH168062 \\
\hline AL-M11 sy & GYO reishi kit & G. lucidum & G. lingzhi & MH160066/MH168063 \\
\hline$A L-M 12_{c d}$ & GYO reishi kit & G. lucidum & G. lingzhi & MH160067/MH168064 \\
\hline$A L-M 13_{s d}$ & GYO reishi kit & G. lucidum s.I. & G. resinaceum s.l.ch & MH160068/MH168065 \\
\hline AL-M14 sd & GYO reishi kit & G. lucidum s.I. & G. resinaceum s.l.ch & MH160069/MH168066 \\
\hline$A L-M 15_{s d}$ & GYO reishi kit & G. lucidum & G. lingzhi & MH160070/MH168067 \\
\hline$A L-M 16_{c d}$ & GYO reishi kit & G. Iucidum & G. Iucidum & MH160071/MH168068 \\
\hline$A L-M 17_{\text {sd }}$ & GYO reishi kit & G. curtisii & G. curtisii & MH160072/MH168069 \\
\hline $\mathrm{AL}-\mathrm{R} 1_{\mathrm{ca}}$ & Manufactured product & G. lucidum & G. lingzhi $i_{\mathrm{cu}}$ & MH160073/- \\
\hline $\mathrm{AL}-\mathrm{R} 2_{\mathrm{ca}}$ & Manufactured product & G. lucidum & G. lingzhi $i_{\mathrm{mbb}}$ & MH160074/- \\
\hline$A L-R 3_{c a}$ & Manufactured product & G. lucidum & G. lingzhi $i_{\mathrm{cu}}$ & MH160075/- \\
\hline $\mathrm{AL}-\mathrm{R} 4_{\mathrm{ca}}$ & Manufactured product & G. Iucidum/Lentinula edodes & FAILED $_{\text {ifb }}$ & $-/-$ \\
\hline $\mathrm{AL}-\mathrm{R} 5_{\mathrm{ca}}$ & Manufactured product & G. lucidum & G. lingzhi $i_{\mathrm{mbb}}$ & MH160076/- \\
\hline $\mathrm{AL}-\mathrm{R} 6_{\mathrm{ca}}$ & Manufactured product & G. lucidum & G. applanatum $m_{\mathrm{mfb}}$ & MH160077/- \\
\hline $\mathrm{AL}-\mathrm{R} 7_{\mathrm{ca}}$ & Manufactured product & G. lucidum & G. lingzhisp & MH160078/- \\
\hline$A L-R 8_{c a}$ & Manufactured product & G. lucidum & G. lingzhi ifb & MH160079/- \\
\hline$A L-R 9_{p o}$ & Manufactured product & G. lucidum & G. lingzhisp & MH160080/- \\
\hline AL-R10po & Manufactured product & G. lucidum & G. lingzhi $i_{\mathrm{ifb}}$ & MH160081/- \\
\hline $\mathrm{AL}-\mathrm{R} 11_{\mathrm{ca}}$ & Manufactured product & G. tsugai $^{5}$, G. Iucidum, G. applanatum & FAILED $_{\mathrm{cu}}$ & $-/-$ \\
\hline AL-R12po & Manufactured product & G. Iucidum & FAILED $\mathrm{mfb}_{\mathrm{b}}$ & $-/-$ \\
\hline $\mathrm{AL}-\mathrm{R} 13_{\mathrm{ca}}$ & Manufactured product & G. lucidum s.l. & G. lingzhi $i_{\mathrm{cu}}$ & MH160082/- \\
\hline AL-R14po & Manufactured product & G. Iucidum & G. lingzhisp & MH160083/- \\
\hline$A L-R 15_{c o}$ & Manufactured product & Ganoderma sp. & G. lingzhind & MH160084/- \\
\hline $\mathrm{AL}-\mathrm{R} 16_{\mathrm{ta}}$ & Manufactured product & unknown & FAILED ${ }_{\mathrm{mfb}}$ & $-1-$ \\
\hline $\mathrm{AL}-\mathrm{R} 17_{\mathrm{ca}}$ & Manufactured product & G. lucidum s.I. & G. lingzhi iff & MH160085/- \\
\hline AL-R18 $\mathrm{ca}$ & Manufactured product & G. Iucidum & FAILED $_{\text {ifb }}$ & $-/-$ \\
\hline AL-R19ca & Manufactured product & G. lucidum & G. lingzhi $i_{\mathrm{mbb}}$ & MH160086/- \\
\hline $\mathrm{AL}-\mathrm{R} 2 \mathrm{O}_{\text {te }}$ & Manufactured product & G. lucidum & FAILED $\mathrm{mfb}$ & $-/-$ \\
\hline
\end{tabular}

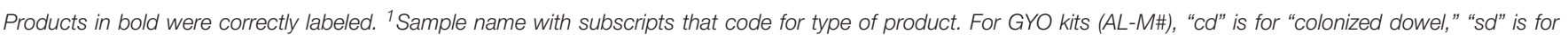

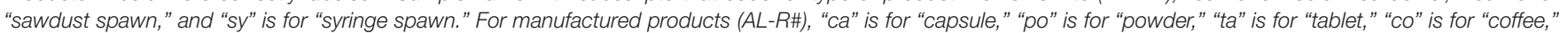

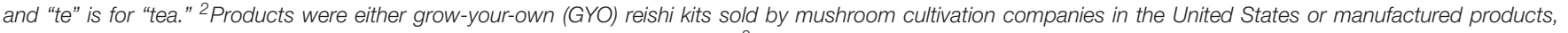

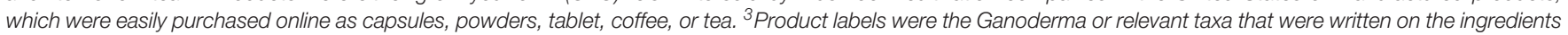

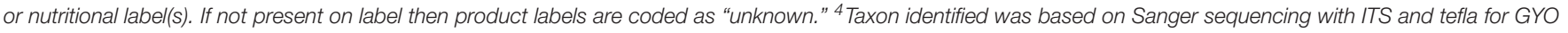

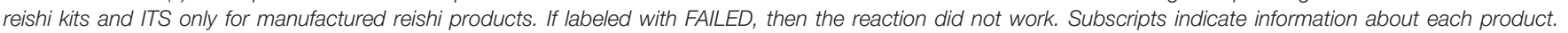

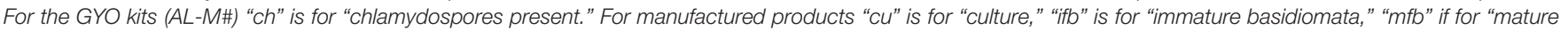
basidiomata," "sp" is for "only spores," and "nd" is for "nothing detected." "Presumably, this product meant to have G. tsugae not G. tsugai.

patterns, we expect that G. lucidum and other laccate Ganoderma species do not have a global distribution unless they have been introduced by humans. Yet the common practice for the past century has been to use the epithet "G. lucidum" for laccate Ganoderma species found on hardwoods across Asia, Europe, and North America. This cross-continental taxonomic lumping has made it impossible to draw clear inferences on the biology and chemistry of this culturally and ecologically important genus of wood decay fungi, as it is often unclear which species was under examination in any particular study. This taxonomic problem has been extended to the commercial medicinal fungi industry where products containing any laccate Ganoderma species are generally labeled as containing G. lucidum without additional information about the origin of the product or whether it was produced from multiple sources or species. The discovery of distinct species within the G. lucidum species complex has raised 


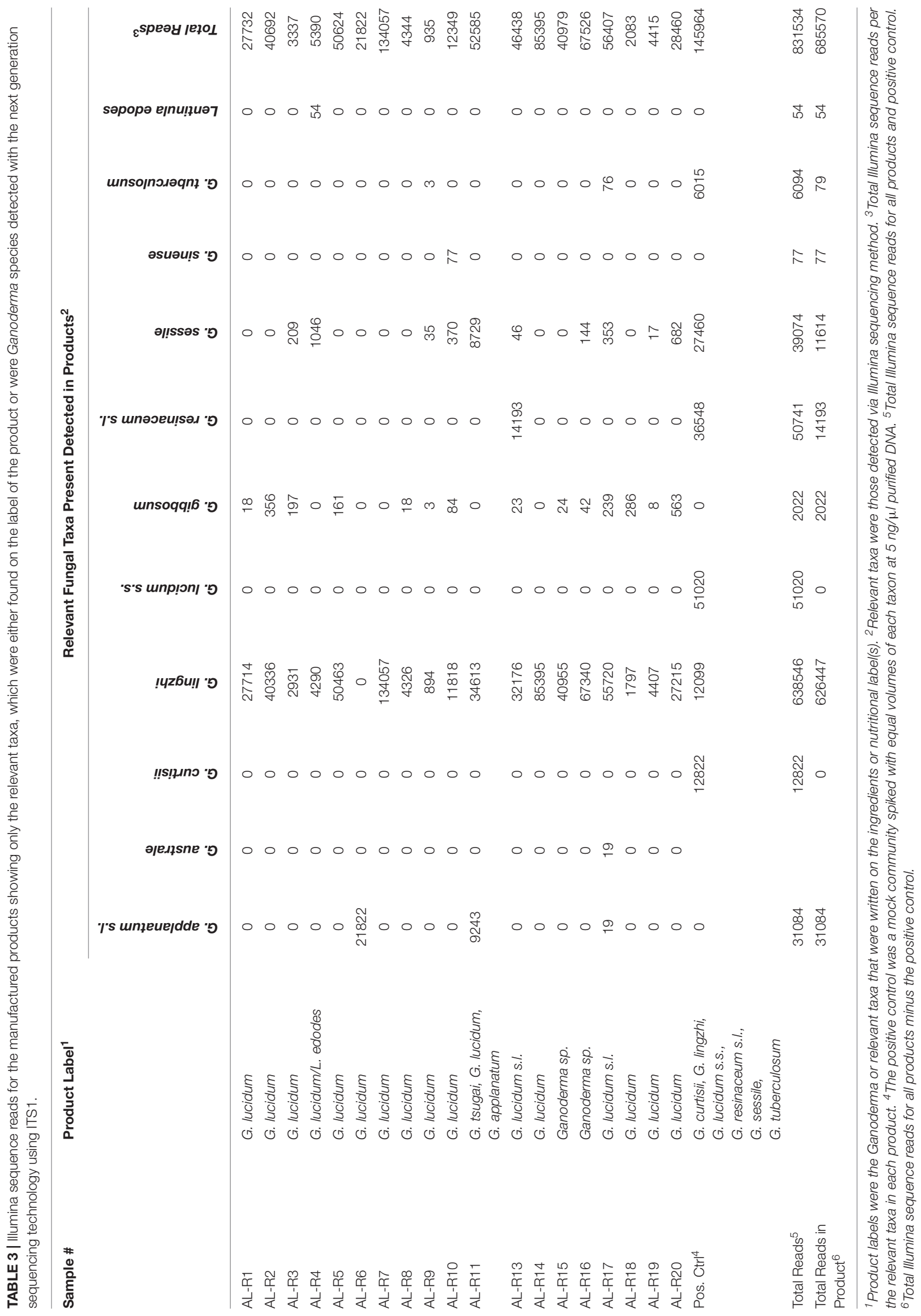




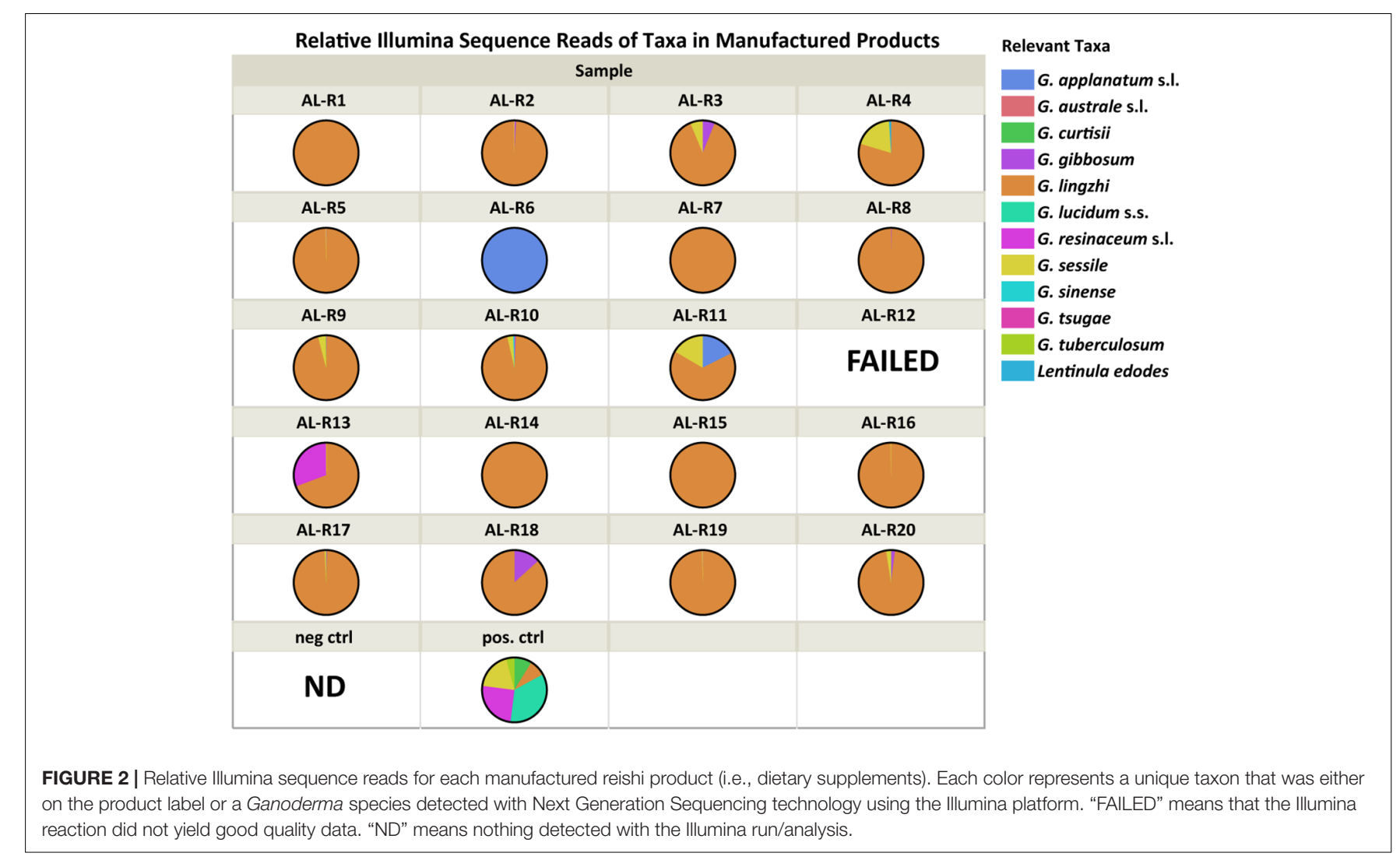

questions about inferences drawn in previous ecological studies of this genus (Loyd et al., 2018a,b). It also elucidates potential sources of variability in product chemistries and efficacies, and presents challenges for potential drug discovery efforts.

Of the 36 GYO kits and manufactured reishi products that were labeled as including G. lucidum in our survey, we found that $86 \%$ of them included a product substitution. Most of the time G. lingzhi was substituted for G. lucidum. As a medicinal product, this reishi "substitution" is probably more appropriate than the G. lucidum indicated on the label. G. lingzhi, which is native to East Asia, was recently circumscribed as one of the species previously mislabeled as G. lucidum sensu lato in Asia (Cao et al., 2012). G. lingzhi is likely the species that should properly be associated with the common names "reishi" and "lingzhi", used in Chinese medicine (Dai et al., 2017). We also found evidence that other taxa were substituted for G. lucidum, including G. applanatum sensu lato, G. australe sensu lato, G. curtisii, G. gibbosum, G. resinaceum sensu lato, and G. sessile. These taxa were sold as GYO kits or produced $>5 \%$ of the Illumina sequence reads for an individual manufactured reishi product. All of these species are genetically distinct from G. lucidum, which is a species native to the temperate forests of Europe and some parts of China (Cao et al., 2012; Wang et al., 2012). These other species are also morphologically quite distinct from each other. In fact, G. applanatum, G. australe, and G. gibbosum have non-laccate (dull) pilei and belong to the subgenus Elfvingia (Moncalvo et al., 1995b). G. curtisii and G. resinaceum produce laccate (shiny) pilei as in G. luccidum but belong to two distinct subclades within the subgenus Ganoderma (Zhou et al., 2015). Based on the genetic diversity of the taxa sold as GYO kits and manufactured reishi products, it is likely that there are significant differences in the quality and quantity of medicinally relevant chemicals among the products being sold as "reishi," and specified as "G. lucidum."

Species substitutions in consumer products have been observed in other medicinal and culinary fungi as well. These include Cordyceps, Boletus and Phellinus species, among others (Dentinger and Suz, 2014; Raja et al., 2017). Raja et al. (2017) found that many of the products labeled with Cordyceps sinensis, a highly prized medicinal fungus, were identified based on DNA barcodes to Tolypocladium inflatum that belong to the same order of Hypocreales as C. sinensis. Similarly, Dentinger and Suz (2014) identified three novel species of Boletus in a single commercially sold packet of Chinese porcini mushrooms, assumed to be Boletus edulis, at a London supermarket. Furthermore, Newmaster et al. (2013) revealed that the herbal medicine industry (i.e., medicinal plant products) suffers from the same mislabeling problems. The authors showed that $68 \%$ of products tested (30 of 44) had species substitutions and about $33 \%$ of these products had fillers or contaminants that were not listed on the product label. Furthermore, some of the unlabeled contaminants/fillers were found to pose potential health risks to consumers (Newmaster et al., 2013). We detected a different species of Ganoderma than the one indicated on the product label in all but two of the products we tested. In a more limited sampling, Raja et al. (2017) also showed that reishi products labeled as G. lucidum were either $G$. sichuanense or $G$. resinaceum. G. sichuanense was 
circumscribed prior to G. lingzhi, but the holotype was not consistent with the original description of $G$. sichuanense. In fact, the holotype of $G$. sichuanense has morphology and ITS sequences that are more similar to Ganoderma weberianum. Furthermore, this confusion is exacerbated by the fact that the two names $G$. lingzhi and $G$. sichuanense continue to be used in the literature (Cao et al., 2012; Wang et al., 2012; Zhou et al., 2015; Hennicke et al., 2016; Dai et al., 2017; Raja et al., 2017) for the same species, despite the confusion arisen from the type specimens/sequences of $G$. sichuanense. As mentioned in previous studies (Cao et al., 2012; Zhou et al., 2015; Dai et al., 2017), we propose that the name G. lingzhi should be used until the taxonomy of $G$. sichuanense is resolved.

$\mathrm{Wu}$ et al. (2017) tested the quality of reishi supplement products by evaluating the polysaccharide and triterpene profiles using chromatography and saccharide mapping, and found that only $26.3 \%$ of the products tested were consistent with the triterpene and polysaccharide profile of an authenticated G. lucidum sensu stricto sample. Based on our results, most manufactured reishi products (i.e., dietary supplements), and nearly half of the products from the GYO kits sold in the United States contained the Asian species G. lingzhi despite being labeled as G. lucidum. Hennicke et al. (2016) showed that G. lucidum and G. lingzhi were not only genetically distinct based on the beta-tubulin gene, but were also chemically different. Extracts of $G$. lingzhi produced significantly more triterpenic acids than extracts made with G. lucidum sensu stricto (Hennicke et al., 2016). Although the products were mislabeled, current evidence suggests that G. lingzhi is the most widely used species in traditional Chinese medicine. More data are needed, however, to verify that other taxa were not used traditionally as well (Cao et al., 2012; Dai et al., 2017). In addition to G. lingzhi, the GYO kits were found to include G. curtisii, G. lucidum, G. sessile, and G. resinaceum sensu lato. Of these taxa, G. curtisii and G. sessile are native to the United States, whereas G. resinaceum and G. lucidum are native to Europe. Furthermore, G. curtisii is the North American sister taxon to the widely cultivated G. lingzhi (Zhou et al., 2015), and could potentially share similar ecological, biological and chemical properties. However, with the exception of G. lucidum sensu stricto, no study has evaluated the medicinal properties of these Ganoderma species, and how they relate to the widely cultivated G. lingzhi in Asia.

Our microscopic analyses indicated that in addition to species variability, companies are making manufactured reishi products out of various tissue types (e.g., basidiomata, mycelium, spores, etc.). Just as there is a dearth of research exploring biochemical differences among the newly elucidated Ganoderma taxa, few studies have investigated the differences in production of medicinally relevant chemicals produced within different tissue types. Heleno et al. (2012) investigated the differences in antioxidant potential of fruiting bodies, mycelium and spores of G. lucidum sensu stricto. The authors showed that phenolic compounds produced by G. lucidum had higher antioxidant potential than the polysaccharides (Heleno et al., 2012). Furthermore, extracts from fruiting bodies had the highest level of phenolics compared to the other tissue types (Heleno et al., 2012). Lastly, they found that mycelium had the lowest level of phenolics, but the highest level of polysaccharides (Heleno et al., 2012). Similarly, Sudheer et al. (2018) evaluated cultivation conditions (e.g., carbon dioxide concentration and light) that promote stipe elongation ("antler form") vs. pileus formation ("kidney-shaped cap") (Figure 3), and biochemical properties associated with each one of these unique isolate of G. lucidum. The "antler form" showed significantly more production of phenolics, flavonoids, polysaccharides and ganodermin, compared to the fruiting bodies that formed a true pileus (kidneyshaped cap form) (Sudheer et al., 2018). As pharmaceutical research continues to identify specific medicinally valuable compounds produced by Ganoderma species and characterize their biological activities, more research investigating the production of relevant compounds within each tissue type is warranted to improve product efficacy and consistency, and/or to lay the groundwork for the biomanufacturing of specific desirable compounds.

In addition to the medicinal relevance of the diverse Ganoderma species, there are many ecological implications
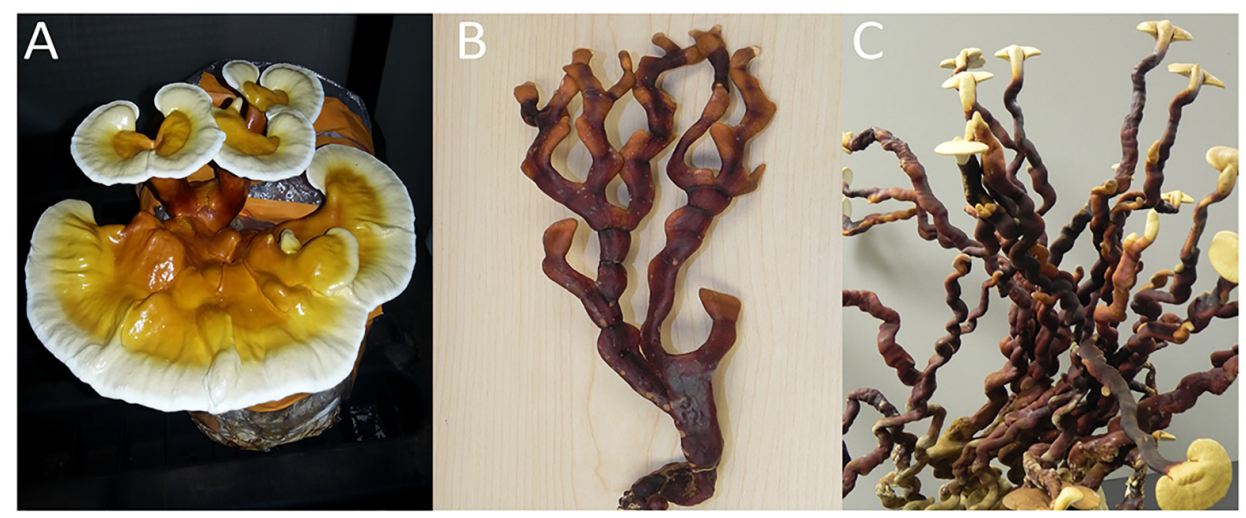

FIGURE 3 | Fruiting bodies of G. lingzhi produced from GYO kits sold as G. lucidum. (A) "Kidney-shaped cap form" basidiomata, which is produced with good ventilation, (B) "antler form" basidiomata, which is produced under poor ventilation and high $\mathrm{CO}_{2}$, and (C) "anter form" basidiomata that transitioned into the "kidney-shaped cap form" after being exposed to better ventilation. 
in regard to cultivating non-native Ganoderma taxa outside of their native range. Of the 17 GYO kits purchased by companies in the United States, 11 purchased kits were of Ganoderma taxa that are not native to the United States. These taxa included G. lingzhi (native to Asia), G. lucidum (native to Europe and Asia), and G. resinaceum sensu lato (native to Europe). Previously, it was shown that monokaryotic isolates of the North American native G. sessile (previously considered in publications as G. lucidum) were compatible with monokaryotic European isolates of $G$. resinaceum, a species native to Europe (Adaskaveg and Gilbertson, 1986). Phylogenetic studies have shown that these species are sister taxa within the resinaceum subclade (Zhou et al., 2015). It is therefore possible that gene interchange could occur between related native and non-native Ganoderma taxa. When species are cultivated the potential for escape is heightened because large numbers of basidiomata are typically produced in a small area. The escape into the wild of billions of propagules (i.e., basidiospores) of a single genotype could create a genetic bottleneck in the wild populations. This would ultimately lead to a reduction of genetic diversity in wild populations. This phenomenon has been previously shown with the common button mushroom Agaricus bisporus in California, where cultivated genotypes have escaped cultivation and displaced native genotypes (Kerrigan and Ross, 1989; Kerrigan, 1995). A similar threat of dominance by a single cultivated genotype has been postulated for the shiitake industry in its native range in Asia (Hibbett and Donoghue, 1996). It is also possible that introduced species or hybrids between native and introduced taxa may be more aggressive wood decay fungi than the native species, which could have unintended consequences. For example, Coetzee et al. (2001) showed that a European genotype of Armillaria mellea, that was causing root rot on oaks and other woody shrubs, was introduced to South Africa over 300 years ago, presumably on nursery stock. More recently, the European species Ganoderma adspersum has been introduced to the San Joaquin Valley of California on almond root stocks, and is causing significant decay of the lower trunk/root flare resulting in tree failures due to windfall (Johnson, 2017). Moreover, in a recent survey of the laccate Ganoderma species in the United States, Loyd (2018) found two small geographically isolated populations of the European species G. lucidum sensu stricto that were presumed to be introduced through nursery stock or the medicinal fungus trade. Conservation studies focusing on the impacts of introduced decay fungi should be conducted to understand the ramifications of cultivating non-native Ganoderma and other commercially produced species in the United States.

Based on the Dietary Supplement Health and Education Act (DSHEA) of 1994, the FDA is not responsible for analyzing the contents of dietary supplements (Dodge et al., 2011). According to the DSHEA, the manufacturer is responsible for the safety and integrity of the product that it sells (Dodge et al., 2011). Given the difficulties in identifying and accurately naming specimens of laccate Ganoderma, blame cannot be placed on any one institution, whether it be the government, academia, growers, manufacturers, or distributors. However, in light of results from this study and others (Newmaster et al., 2013;
Dentinger and Suz, 2014; Raja et al., 2017), the United States. Food and Drug Administration should reconsider the way it regulates the dietary supplement industry, especially medicinal herbs and fungi. In addition, there are few to no regulations on growing non-native Ganoderma species outside their native range. Until more research is conducted regarding the ecological ramifications of growing Ganoderma taxa outside their native range, Ganoderma cultivators should focus on growing regionally specific taxa to avoid any potential escapes with non-native taxa.

Our research shows that GYO kits and manufactured products (i.e., dietary supplements) marketed as G. lucidum contain multiple Ganoderma species. The fact that these products are inaccurately labeled and/or contain a mix of species, but are nonetheless sold for medicinal uses, raises questions regarding the authenticity of the fungal products used by this industry. Important questions are also raised such as: Do all Ganoderma species produce similar quality and quantities of medicinally relevant compounds? Can phylogenetic placement of a Ganoderma species predict the presence or effectiveness of medicinally relevant compounds? Are all Ganoderma preparations (e.g., basidiomata tissues, cultivated mycelium, spores) equally useful for medicinal purposes? Does growing non-native Ganoderma species present risks that they may displace native decay fungi or cause root rot or detrimental decay on native trees? These questions should be addressed in subsequent research focusing on the cultivation and manufacturing of reishi products.

\section{AUTHOR CONTRIBUTIONS}

The conception of the paper was a collaborative idea with AL, BR, MS, and JS. The work was funded by a grant received by AL, JS, and RB. The microscopy and molecular lab work was conducted as a collaborative effort by $\mathrm{AL}, \mathrm{CT}$, and MJ. The manuscript was written by AL. The manuscript was edited and reviewed by AL, $\mathrm{BR}, \mathrm{MJ}$, CT, MS, RB, and JS.

\section{FUNDING}

$\mathrm{AL}, \mathrm{RB}$, and JS received a research grant from the International Society of Arboriculture, Florida Chapter that helped pay for some of this work. In addition, the F. A. Bartlett Tree Experts Company funded some of this research through a foundation grant through the Forest Pathology Lab at the University of Florida. MS, CT, and MJ received funding from the National Institute of Food and Agriculture, United States Department of Agriculture, under award number FLA-PLP-005289 (to MS) and the Institute of Food and Agriculture Sciences at the University of Florida.

\section{ACKNOWLEDGMENTS}

The authors are grateful for the help from Eric Linder and Cassie Newman on this project. 


\section{REFERENCES}

Adaskaveg, J., and Gilbertson, R. (1989). Cultural studies of four North American species in the Ganoderma lucidum complex with comparisons to G. lucidum and G. tsugae. Mycol. Res. 92, 182-191. doi: 10.1016/S0953-7562(89)80010-3

Adaskaveg, J. E., and Gilbertson, R. L. (1986). Cultural studies and genetics of sexuality of Ganoderma lucidum and G. tsugae in relation to the taxonomy of the G. lucidum complex. Mycologia 5, 694-705. doi: 10.2307/3807513

Basnet, B. B., Liu, L., Bao, L., and Liu, H. (2017). Current and future perspective on antimicrobial and anti-parasitic activities of Ganoderma sp.: an update. Mycology 8, 111-124. doi: 10.1080/21501203.2017.1324529

Binns, C. W., Lee, M. K., and Lee, A. H. (2017). Problems and prospects: public health regulation of dietary supplements. Annu. Rev. Public Health 39, 403-420. doi: 10.1146/annurev-publhealth-040617-013638

Boh, B., Berovic, M., Zhang, J., and Zhi-Bin, L. (2007). Ganoderma lucidum and its pharmaceutically active compounds. Biotechnol. Annu. Rev. 13, 265-301. doi: 10.1016/S1387-2656(07)13010-6

Cao, Y., Wu, S.-H., and Dai, Y.-C. (2012). Species clarification of the prize medicinal Ganoderma mushroom "Lingzhi". Fungal Divers. 56, 49-62. doi: 10.1007/s13225-012-0178-5

Chen, S., Xu, J., Liu, C., Zhu, Y., Nelson, D. R., Zhou, S., et al. (2012). Genome sequence of the model medicinal mushroom Ganoderma lucidum. Nat. Commun. 3:913. doi: 10.1038/ncomms 1923

Coetzee, M., Wingfield, B. D., Harrington, T. C., Steimel, J., Coutinho, T. A., and Wingfield, M. J. (2001). The root rot fungus Armillaria mellea introduced into South Africa by early Dutch settlers. Mol. Ecol. 10, 387-396. doi: 10.1046/j.1365294x.2001.01187.x

Dai, Y.-C., Zhou, L.-W., Hattori, T., Cao, Y., Stalpers, J. A., Ryvarden, L., et al. (2017). Ganoderma lingzhi (Polyporales, Basidiomycota): the scientific binomial for the widely cultivated medicinal fungus Lingzhi. Mycol. Prog. 16, 1051-1055. doi: 10.1007/s11557-017-1347-4

Dentinger, B. T., and Suz, L. M. (2014). What's for dinner? Undescribed species of porcini in a commercial packet. PeerJ 2:e570. doi: 10.7717/peerj.570

Dodge, T., Litt, D., and Kaufman, A. (2011). Influence of the dietary supplement health and education act on consumer beliefs about the safety and effectiveness of dietary supplements. J. Health Commun. 16, 230-244. doi: 10.1080/10810730. 2010.529493

Dresch, P., Aguanno, M. N., Rosam, K., Grienke, U., Rollinger, J. M., and Peintner, U. (2015). Fungal strain matters: colony growth and bioactivity of the European medicinal polypores Fomes fomentarius, Fomitopsis pinicola and Piptoporus betulinus. AMB Express 5:4. doi: 10.1186/s13568-014-0093-0

Edgar, R. C., and Flyvbjerg, H. (2015). Error filtering, pair assembly and error correction for next-generation sequencing reads. Bioinformatics 31, 3476-3482. doi: 10.1093/bioinformatics/btv401

Gardes, M., and Bruns, T. D. (1993). ITS primers with enhanced specificity for basidiomycetes-application to the identification of mycorrhizae and rusts. Mol. Ecol. 2, 113-118. doi: 10.1111/j.1365-294X.1993.tb00005.x

Gilbertson, R., and Ryvarden, L. (1986). North American Polypores. Abortiporus to Lindteria. Oslo: Fungiflora.

Heleno, S. A., Barros, L., Martins, A., Queiroz, M. J. R., Santos-Buelga, C., and Ferreira, I. C. (2012). Fruiting body, spores and in vitro produced mycelium of Ganoderma lucidum from Northeast Portugal: a comparative study of the antioxidant potential of phenolic and polysaccharidic extracts. Food Res. Int. 46, 135-140. doi: 10.1016/j.foodres.2011.12.009

Hennicke, F., Cheikh-Ali, Z., Liebisch, T., Maciá-Vicente, J. G., Bode, H. B., and Piepenbring, M. (2016). Distinguishing commercially grown Ganoderma lucidum from Ganoderma lingzhi from Europe and East Asia on the basis of morphology, molecular phylogeny, and triterpenic acid profiles. Phytochemistry 127, 29-37. doi: 10.1016/j.phytochem.2016. 03.012

Hibbett, D. S., and Donoghue, M. J. (1996). Implications of phylogenetic studies for conservation of genetic diversity in shiitake mushrooms. Conserv. Biol. 10, 1321-1327. doi: 10.1046/j.1523-1739.1996.10051321.x

Hong, S. G., and Jung, H. S. (2004). Phylogenetic analysis of Ganoderma based on nearly complete mitochondrial small-subunit ribosomal DNA sequences. Mycologia 96, 742-755. doi: 10.1080/15572536.2005.11832922

Isaka, M., Chinthanom, P., Sappan, M., Danwisetkanjana, K., Boonpratuang, T., and Choeyklin, R. (2015). Antitubercular lanostane triterpenes from cultures of the basidiomycete Ganoderma sp. BCC 16642. J. Nat. Prod. 79, 161-169. doi: 10.1021/acs.jnatprod.5b00826

Jin, X., Ruiz Beguerie, J., Sze, D. M., and Chan, G. C. (2012). Ganoderma lucidum (Reishi mushroom) for cancer treatment. Cochrane Database Syst. Rev. 6:CD007731. doi: 10.1002/14651858.CD007731.pub2

Johnson, B. (2017). Ganoderma Root and Butt Rot: an Emerging Threat to California Almonds, eds B. Johnson and D. M. Rizzo (Davis, CA: University of California).

Joseph, S., Sabulal, B., George, V., Smina, T. P., and Janardhanan, K. K. (2009). Antioxidative and antiinflammatory activities of the chloroform extract of Ganoderma lucidum found in South India. Sci. Pharm. 77, 111-122. doi: 10.3797/scipharm.0808-17

Kalogeropoulos, N., Yanni, A. E., Koutrotsios, G., and Aloupi, M. (2013). Bioactive microconstituents and antioxidant properties of wild edible mushrooms from the island of Lesvos, Greece. Food Chem. Toxicol. 55, 378-385. doi: 10.1016/j. fct.2013.01.010

Katoh, K., Misawa, K., Kuma, K., and Miyata, T. (2002). MAFFT: a novel method for rapid multiple sequence alignment based on fast Fourier transform. Nucleic Acids Res. 30, 3059-3066. doi: 10.1093/nar/gkf436

Kearse, M., Moir, R., Wilson, A., Stones-Havas, S., Cheung, M., Sturrock, S., et al. (2012). Geneious basic: an integrated and extendable desktop software platform for the organization and analysis of sequence data. Bioinformatics 28, 1647-1649. doi: 10.1093/bioinformatics/bts199

Kerrigan, R. W. (1995). Global genetic resources for Agaricus breeding and cultivation. Can. J. Bot. 73, 973-979. doi: 10.1139/b95-347

Kerrigan, R. W., and Ross, I. K. (1989). Allozymes of a wild Agaricus bisporus population: new alleles, new genotypes. Mycologia 81, 433-443. doi: 10.2307/ 3760080

Kõljalg, U., Nilsson, R. H., Abarenkov, K., Tedersoo, L., Taylor, A. F., Bahram, M., et al. (2013). Towards a unified paradigm for sequence-based identification of fungi. Mol. Ecol. 22, 5271-5277. doi: 10.1111/mec.12481

Lai, T., Gao, Y., and Zhou, S. (2004). Global marketing of medicinal Lingzhi mushroom Ganoderma lucidum (W. Curt.: Fr.) Lloyd (Aphyllophoromycetideae) products and safety concerns. Int. J. Med. Mushrooms 6, 189-194. doi: 10.1615/IntJMedMushr.v6.i2.100

Lin, C.-N., Tome, W.-P., and Won, S.-J. (1991). Novel cytotoxic principles of Formosan Ganoderma lucidum. J. Nat. Prod. 54, 998-1002. doi: 10.1021/ np50076a012

Loyd, A. L. (2018). Taxonomy, Biology, Decay Potential, and Pathogenicity of the Laccate (Varnished) Ganoderma species Present in the U.S. Gainesville, FL: University of Florida.

Loyd, A. L., Held, B. W., Linder, E. R., Smith, J. A., and Blanchette, R. A. (2018a). Elucidating wood decomposition by four species of Ganoderma from the United States. Fungal Biol. 122, 254-263. doi: 10.1016/j.funbio.2018.01.006

Loyd, A. L., Linder, E. R., Anger, N. A., Richter, B. S., Blanchette, R. A., and Smith, J. A. (2018b). Pathogenicity of Ganoderma species on landscape trees in the southeastern united states. Plant Dis. doi: 10.1094/PDIS-02-18-0338-RE

Marx, D. H., and Daniel, W. J. (1976). Maintaining cultures of ectomycorrhizal and plant pathogenic fungi in sterile water cold storage. Can. J. Microbiol. 22, 338-341. doi: 10.1139/m76-051

Moncalvo, J.-M., Wang, H.-F., and Hseu, R.-S. (1995a). Gene phylogeny of the Ganoderma lucidum complex based on ribosomal DNA sequences. Comparison with traditional taxonomic characters. Mycol. Res. 99, 1489-1499.

Moncalvo, J.-M., Wang, H.-H., and Hseu, R.-S. (1995b). Phylogenetic relationships in Ganoderma inferred from the internal transcribed spacers and $25 \mathrm{~S}$ ribosomal DNA sequences. Mycologia 87, 223-238. doi: 10.2307/3760908

Mothana, R., Ali, N. A., Jansen, R., Wegner, U., Mentel, R., and Lindequist, U. (2003). Antiviral lanostanoid triterpenes from the fungus Ganoderma pfeifferi. Fitoterapia 74, 177-180. doi: 10.1016/S0367-326X(02)00305-2

Newmaster, S. G., Grguric, M., Shanmughanandhan, D., Ramalingam, S., and Ragupathy, S. (2013). DNA barcoding detects contamination and substitution in North American herbal products. BMC Med. 11:222. doi: 10.1186/17417015-11-222

Nobles, M. K. (1965). Identification of cultures of wood-inhabiting Hymenomycetes. Can. J. Bot. 43, 1097-1139. doi: 10.1139/b65-126

Palmer, J. M., Jusino, M. A., Banik, M. T., and Lindner, D. L. (2018). Nonbiological synthetic spike-in controls and the AMPtk software pipeline improve mycobiome data. PeerJ 6:e4925. doi: 10.7717/peerj.4925 
Paterson, R. R. M. (2006). Ganoderma-a therapeutic fungal biofactory. Phytochemistry 67, 1985-2001. doi: 10.1016/j.phytochem.2006.07.004

Pirone, P. P. (1957). Ganoderma lucidum, a parasite of shade trees. Bull. Torrey Bot. Club 84, 424-428. doi: 10.2307/2482973

Powell, M. (2006). The use of Ganoderma lucidum (Reishi) in the management of histamine-mediated allergic responses. Townsend Lett. 274, 78-82.

Raja, H. A., Baker, T. R., Little, J. G., and Oberlies, N. H. (2017). DNA barcoding for identification of consumer-relevant mushrooms: a partial solution for product certification? Food Chem. 214, 383-392. doi: 10.1016/j.foodchem.2016. 07.052

Ronquist, F., Teslenko, M., Van Der Mark, P., Ayres, D. L., Darling, A., Höhna, S., et al. (2012). MrBayes 3.2: efficient Bayesian phylogenetic inference and model choice across a large model space. Syst. Biol. 61, 539-542. doi: 10.1093/sysbio/ sys029

Sanodiya, B. S., Thakur, G. S., Baghel, R. K., Prasad, G., and Bisen, P. (2009). Ganoderma lucidum: a potent pharmacological macrofungus. Curr. Pharm. Biotechnol. 10, 717-742. doi: 10.2174/138920109789978757

Schoch, C. L., Seifert, K. A., Huhndorf, S., Robert, V., Spouge, J. L., Levesque, C. A., et al. (2012). Nuclear ribosomal internal transcribed spacer (ITS) region as a universal DNA barcode marker for Fungi. Proc. Natl. Acad. Sci. U.S.A. 109, 6241-6246. doi: 10.1073/pnas.1117018109

Sinclair, W. A., and Lyon, H. H. (2005). Diseases of Trees and Shrubs. New York, NY: Comstock Publishing Associates.

Stamatakis, A. (2014). RAxML version 8: a tool for phylogenetic analysis and post-analysis of large phylogenies. Bioinformatics 30, 1312-1313. doi: 10.1093/ bioinformatics/btu033

Stamets, P. (2000). Growing Gourmet and Medicinal Mushrooms. Berkeley, CA: Ten Speed Press.

Sudheer, S., Taha, Z., Manickam, S., Ali, A., and Cheng, P. G. (2018). Development of antler-type fruiting bodies of Ganoderma lucidum and determination of its biochemical properties. Fungal Biol. 122, 293-301. doi: 10.1016/j.funbio.2018. 01.007

Upton, R., and Petrone, C. (2000). American Herbal Pharmacopoeia-Reishi Mushroom-Ganoderma Lucidum. New York, NY: American Herbal Pharmacopoeia.

Wang, D.-M., Wu, S.-H., Su, C.-H., Peng, J.-T., Shih, Y.-H., and Chen, L.-C. (2009). Ganoderma multipileum, the correct name for 'G. lucidum' in tropical Asia. Bot. Stud. 50, 451-458.
Wang, H., and Ng, T. (2006). Ganodermin, an antifungal protein from fruiting bodies of the medicinal mushroom Ganoderma lucidum. Peptides 27, 27-30. doi: 10.1016/j.peptides.2005.06.009

Wang, X. C., Xi, R. J., Li, Y., Wang, D. M., and Yao, Y. J. (2012). The species identity of the widely cultivated Ganoderma, 'G. lucidum' (Ling-zhi), in China. PLoS One 7:e40857. doi: 10.1371/journal.pone.0040857

Welti, S., and Courtecuisse, R. (2010). The Ganodermataceae in the French West Indies (Guadeloupe and Martinique). Fungal Divers. 43, 103-126. doi: 10.1007/ s13225-010-0036-2

White, T. J., Bruns, T., Lee, S., and Taylor, J. (1990). "Amplification and direct sequencing of fungal ribosomal RNA genes for phylogenetics," in PCR Protocols: A Guide to Methods and Applications, eds M. A. Innis, D. H. Gelfand, J. J. Sninsky, and T. J. White (San Diego, CA: Academic Press), 315-322.

Wu, D.-T., Deng, Y., Chen, L.-X., Zhao, J., Bzhelyansky, A., and Li, S.-P. (2017). Evaluation on quality consistency of Ganoderma lucidum dietary supplements collected in the United States. Sci. Rep. 7:7792. doi: 10.1038/s41598-01706336-3

Zhao, S., Guo, Y., Liu, Q., Wang, H., and Ng, T. (2009). Lectins but not antifungal proteins exhibit anti-nematode activity. Environ. Toxicol. Pharmacol. 28, 265-268. doi: 10.1016/j.etap.2009.05.003

Zhong, J.-J., and Xiao, J.-H. (2009). Secondary Metabolites from Higher Fungi: Discovery, Bioactivity, and Bioproduction. Biotechnology in China I. Berlin: Springer, 79-150. doi: 10.1007/10_2008_26

Zhou, L.-W., Cao, Y., Wu, S.-H., Vlasák, J., Li, D.-W., Li, M.-J., et al. (2015). Global diversity of the Ganoderma lucidum complex (Ganodermataceae, Polyporales) inferred from morphology and multilocus phylogeny. Phytochemistry 114, 7-15. doi: 10.1016/j.phytochem.2014.09.023

Conflict of Interest Statement: The authors declare that the research was conducted in the absence of any commercial or financial relationships that could be construed as a potential conflict of interest.

Copyright (c) 2018 Loyd, Richter, Jusino, Truong, Smith, Blanchette and Smith. This is an open-access article distributed under the terms of the Creative Commons Attribution License (CC BY). The use, distribution or reproduction in other forums is permitted, provided the original author(s) and the copyright owner(s) are credited and that the original publication in this journal is cited, in accordance with accepted academic practice. No use, distribution or reproduction is permitted which does not comply with these terms. 